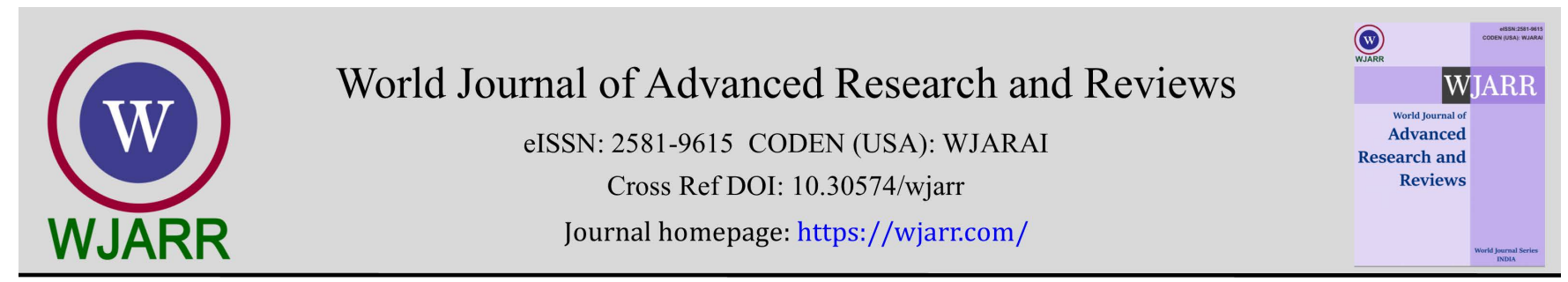

(RESEARCh ARTICLE)

\title{
The definitive cause of little ice age temperatures
}

\author{
Burl Calvin Henry* \\ Retired IBM Senior Engineer, United States, America.
}

World Journal of Advanced Research and Reviews, 2022, 13(02), 516-518

Publication history: Received on 14 January 2022; revised on 18 February 2022; accepted on 20 February 2022

Article DOI: https://doi.org/10.30574/wjarr.2022.13.2.0170

\begin{abstract}
Analysis of the Central England Instrumental Temperatures data set (1659-present) has provided the answer as to the cause of the decreased temperatures during the Little Ice Age (LIA) (and undoubtedly, also those of all other Ice Ages).

The decreased temperatures were caused by the injection of reflective (dimming) Sulfur Dioxide (SO2) aerosols into the stratosphere from extensive occurrences of VEI4-VEI7 volcanic eruptions.
\end{abstract}

Keywords: Climate Change; Little Ice Age; Early Instrumental Temperatures; Volcanic SO2 aerosols

\section{Introduction}

One of the most enduring questions about Earth's climate has been what has caused its various Ice Ages, including the LIA, whose beginning is frequently associated with the Indonesian VEI7 eruption of Mount Rinjani (Samalas), in 1250 [1].

Explanations for the decreased LIA temperatures have included Milanovich cycles, changing intensities of the incoming solar/cosmic ray flux, decreased sunspot activity, and large volcanic eruptions (although volcanic eruptions have largely been dismissed as the cause, because it was thought that the temporary cooling effect of well-separated VEI5-VEI7 volcanic eruptions would likely have been unable to maintain the cold temperatures experienced over the 600 -year course of the LIA $(\sim 1250-1850)$.

The longest instrumental record of temperatures known is the Central England (Lancashire-London-Bristol) data set [2], which began in 1659 and has continued to the present, being known as the Hadley Centre Central England Temperatures (HadCET) data set [2], which is shown below:

Since the data set includes approx. 200 years of the LIA, including all but 15 years of the "Maunder Minimum" (16451715), and the Dalton Minimum (1790-1830, or 1796-1820, per Wikipedia), both being periods of low sunspot activity, it was decided to analyze that period in greater detail, especially since the downward temperature excursions constantly fluctuated, NOT what would be expected from a quiet sun.

\footnotetext{
${ }^{*}$ Corresponding author: Burl Henry

Retired IBM Senior Engineer, United States, America.
}

Copyright $(2022$ Author(s) retain the copyright of this article. This article is published under the terms of the Creative Commons Attribution Liscense 4.0. 


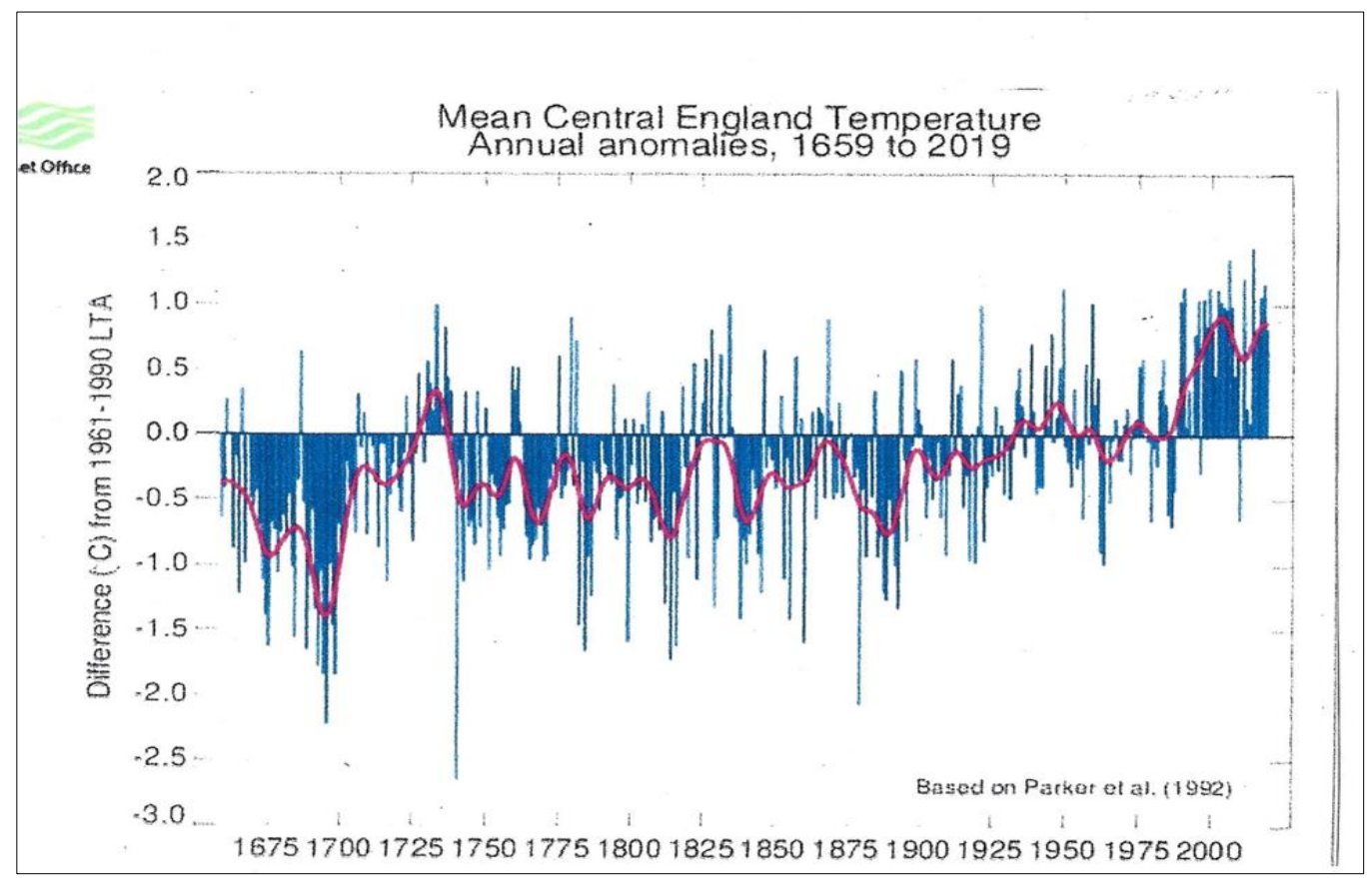

Figure 1 Central England Instrumental Temperatures Data Set

\section{Procedure}

In an effort to understand the cause of the fluctuations, the data set graph was enlarged 400X, giving a horizontal scale of $1 \mathrm{~mm}=1.2$ years.

The portion of the graph showing the anomalous median temperatures below $0.0 \mathrm{deg}$. C. [with respect to the average of 1961-1990 temperatures] (14 deg. C), for the period between 1659 and 1875], is shown below,

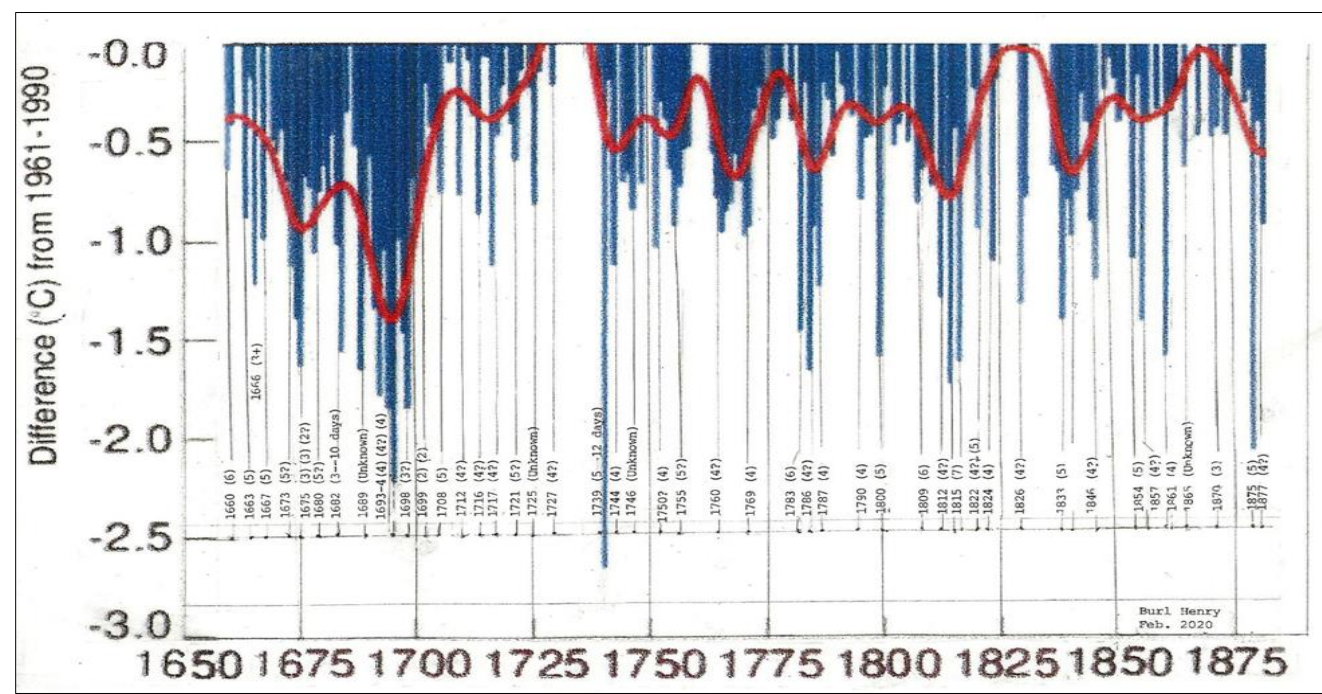

Figure 2 Instrumental Temperature decreases, latter third of LIA

\section{Discussion}

The graph was analyzed by dropping a vertical line down from most downward excursions to a base line, then finding the year of intersection with the base line. 
With very few exceptions, all temperature decreases coincided with the date of known volcanic eruptions, whose date and Volcanic Explosivity Index (VEI) have been added to the graph [3].

The few exceptions show a temperature decrease without a known eruption, which probably represents sea-bottom eruptions which made their presence known by their $\mathrm{SO}_{2}$ aerosol emissions, which temporarily affected global temperatures.

What is somewhat surprising is the fact that many of the temperature decreases are due to VEI4 eruptions (assuming that their VEI's have been accurately assigned), who's cooling effect has been dismissed in the past.

It is also notable that each temperature decrease lasts only as long as its volcanic $\mathrm{SO}_{2}$ aerosols remain in the atmosphere (about 2 -3 years, VEI4-6). This completely eliminates any hypothetical cooling due to low sunspot activity, or to any other solar or cosmic dimming event, where temperatures would not fluctuate on such a short time scale.

(The extent of the downward excursions shown is affected by the ENSO temperature at the time of eruption, geographical location, and plume altitude, sulfurous content of the plume, a closely following eruption, and possible errors in assigning a VEI, so that the magnitude of a given VEI can vary wildly).

Volcanos decrease temperatures by spewing sulfurous gasses into the stratosphere, where they are converted into dimming $\mathrm{SO}_{2}$ aerosols (fine droplets of sulfuric acid). With respect to Figure 1, every downward excursion is due to a volcanic eruption (or eruptions), and every upward excursion represents an interval (typically 3 years, or more) between eruptions, where circulating $\mathrm{SO}_{2}$ aerosols have had time to settle out of the atmosphere, and cause temperatures to rise because of the cleansed air.

\section{Conclusion}

The analysis of the Had CET data set has:

- Demolished the hypothesis that low sunspot activity will cause global cooling. ALL cooling events during solar minimums were associated with volcanic eruptions.

- Shown that all cooling 1660-1875 was caused by increased levels of SO2 aerosols in the atmosphere from volcanic eruptions. This SO2 cooling effect has continued to the present.

- Shown that proxy temperature measurements suggesting decreased solar activity are actually the result of circulating quantities of SO2 aerosols in the atmosphere, which decreases the amount of incoming radiation that creates the proxies.

- Proven that the Little Ice Age was a world-wide event, caused by a period of increased volcanism around the globe. The same temperature changes observed over Central England would also have been experienced globally.

Barring any new phenomenon, if Earth experiences any anomalous cooling in the foreseeable future, it will be due to increased SO2 aerosol emissions into the atmosphere, of either volcanic or anthropogenic origin.

\section{References}

[1] Mount Rinjani (Samalas), https://sosstjoe.org/qfhytcg/mount-rinjani--eruption-1257.html

[2] Met Offices Hadley Centre Observations Data Sets: Hadobs.metoffice.com/hadcet/index.html

[3] Volanoes of the World, Third Edition (2010), Smithsonian Institution, Washington, D.C. Siebert, et al. 